\title{
Jungermannenone A and B induce ROS- and cell cycle-dependent apoptosis in prostate cancer cells in vitro
}

\author{
Yan-xia GUO ${ }^{1}$, Zhao-min LIN $^{2}$, Mei-juan WANG ${ }^{1}$, Yi-wen DONG ${ }^{1}$, Huan-min NIU ${ }^{1}$, Charles YF YOUNG ${ }^{3}$, Hong-xiang LOU ${ }^{2}$, \\ Hui-qing YUAN ${ }^{1, *}$ \\ ${ }^{1}$ Department of Biochemistry and Molecular Biology, Shandong University School of Medicine, Ji-nan 250012, China; ${ }^{2}$ Department of \\ Natural Product Chemistry, Shandong University School of Pharmaceutical Sciences, Ji-nan 250012, China; ${ }^{3}$ Department of Urology, \\ Mayo Clinic College of Medicine, Mayo Clinic, Rochester, MN 55905, USA
}

Aim: Jungermannenone A and B (JA, JB) are new ent-kaurane diterpenoids isolated from Chinese liverwort Jungermannia fauriana, which show anti-proliferation activities in cancer cells. In this study we investigated the mechanisms underlying the anticancer action of JA and JB in PC3 human prostate cancer cells in vitro.

Methods: A panel of 9 human cancer cell lines was tested. Cell proliferation was assessed with a real-time cell analyzer and MTT assay. Cell apoptosis, cell cycle distribution and ROS levels were measured using cytometry. Mitochondrial damage was examined by transmission electron microscopy. DNA damage was detected with comet assay. Apoptotic, DNA damage- and cell cycle-related proteins were analyzed using Western blotting. The expression of DNA repair genes was measured with qRT-PCR.

Results: Both JA and JB exerted potent anti-proliferative action against the 9 cancer cell lines, and PC3 cells were more sensitive with $\mathrm{IC}_{50}$ values of $1.34 \pm 0.09$ and $4.93 \pm 0.20 \mu \mathrm{mol} / \mathrm{L}$, respectively. JA $(1.5 \mu \mathrm{mol} / \mathrm{L})$ and JB $(5 \mu \mathrm{mol} / \mathrm{L})$ induced PC3 cell apoptosis, which was attenuated by the caspase inhibitor Z-VAD. Furthermore, both JA and JB caused mitochondrial damage and ROS accumulation in PC3 cells, whereas vitamin C blocked the ROS accumulation and attenuated the cytotoxicity of JA and JB. Moreover, both JA and JB induced DNA damage, accompanied by downregulated DNA repair proteins Ku70/Ku80 and RDA51. JA induced marked cell cycle arrest at the $G_{0} / G_{1}$ phase, which was related to c-Myc suppression, whereas JB enforced the cell cycle blockade in the $G_{2} / M$ phase, which associated with activation of the JNK signaling.

Conclusion: Both JA and JB induce prostate cancer apoptosis via ROS accumulation and induction of cell cycle arrest.

Keywords: jungermannenones; ent-kaurane diterpenoids; prostate cancer; apoptosis; ROS; DNA damage; cell cycle arrest; c-Myc; JNK; Z-VAD; vitamin C

Acta Pharmacologica Sinica (2016) 37: 814-824; doi: 10.1038/aps.2016.26; published online 2 May 2016

\section{Introduction}

Prostate cancer $(\mathrm{PCa})$ remains the major cause of cancer deaths among males. The mortality of this disease is related to malignant metastasis when androgen-depletion therapy becomes ineffective and the disease advances to castration-resistant prostate cancer $(\mathrm{CRPC})^{[1]}$. There are limited treatment strategies for advanced CRPC ${ }^{[2,3]}$. Currently, docetaxel, a plant alkaloid derivative, and cabazitaxel, a second-generation semisynthetic taxane, have been used to treat advanced CRPC ${ }^{[2,4]}$. However, they only modestly improve the quality of life and survival conditions in these patients ${ }^{[2,5]}$. Many naturally

\footnotetext{
*To whom correspondence should be addressed.

E-mail lyuanhq@sdu.edu.cn

Received 2015-12-23 Accepted 2016-03-21
}

occurring chemicals are being actively sought, due to their diverse structures and unique mechanisms of action for treating cancers, including CRPC ${ }^{[6]}$.

Cell death induced by cytotoxic agents is critical in cancer treatment aimed at modulating the associated pathways. For example, curcumin-induced apoptosis involves activation of p38 mitogen-activated protein kinase, down-regulation of Akt signaling, and suppression of oncogenic Bcl-2 and survivin expression $^{[7,8]}$. Berberine, an isoquinoline alkaloid isolated from plants, has been shown to suppress the growth of various tumor cells through its ability to modulate key signaling pathways and molecules, including NF-kB, Bcl- $\mathrm{x}_{\mathrm{L}}$, Cyclin D1, c-Jun and c-Fos ${ }^{[9,10]}$. Berberine also induces cellular apoptosis through a decrease in mitochondrial transmembrane potential $^{[10]}$. Retigeric acid B, a pentacyclic triterpenic acid from 
Lobaria kurokawae Yoshim, induces ROS production, decreases $\mathrm{mt} \Delta \psi$, and inhibits the PI3K/Akt/mTOR pathway, thereby inducing PCa cell death ${ }^{[1]]}$.

ROS may be generated after ligand-receptor interactions and functions as specific second messengers in signaling cascades involved in cell proliferation, differentiation, or apoptosis. An increase in intracellular ROS has been demonstrated to activate the c-Jun N-terminal kinase (JNK), p38 MAPK and ERK1/2 signaling pathways ${ }^{[12]}$. JNKs have been implicated in streptococcus pneumonia and $\mathrm{H}_{2} \mathrm{O}_{2}$-induced apoptosis of endothelial cells ${ }^{[13,14]}$. Therefore, the induction of ROS acts as a mechanism by which many chemicals exert their antitumor activity $^{[15]}$. Among many oncogenic proteins, c-Myc plays an important role in cell cycle progression, cellular transformation, and even apoptosis ${ }^{[16-18]}$. Given that over-expression is a common feature in various human tumors ${ }^{[17,18]}$, the downregulation of c-Myc, resulting in a $\mathrm{G}_{0} / \mathrm{G}_{1}$ arrest and reduction in the growth rate, also contributes to the inhibitory effect of antitumor drugs ${ }^{[1,20]}$.

Most recently, we have reported that two new ent-kaurane diterpenoids, Jungermannenone A (JA) and Jungermannenone B (JB), from the Chinese liverwort Jungermannia fauriana ${ }^{[21]}$, show potential anti-proliferation activity with a low $\mathrm{IC}_{50}$ against a panel of cancer cell lines. The present study was designed to uncover the cellular/molecular basis by which JA and JB exert their antitumor effects, in addition to their ability to modify protein thiols through the Michael reaction and the depletion of glutathione, mainly in PCa cells.

\section{Materials and methods}

\section{Cell culture and treatments}

The human prostate cancer PC 3 and DU145 cell lines, myelogenous leukemia cell line K562, non-small cell lung cancer cell line A549 and NCI-H1299, small-cell lung cancer cell line NCIH446, and human breast cancer MCF-7 cell line were cultured in RPMI-1640 medium (HyClone, Logan, UT, USA) supplemented with $10 \%$ fetal bovine serum (HyClone, Logan, UT, USA), $100 \mathrm{U} / \mathrm{mL}$ penicillin and $100 \mu \mathrm{g} / \mathrm{mL}$ streptomycin. The human prostate cancer LNCaP cell line was cultured in RPMI1640 medium (HyClone, Logan, UT, USA) supplemented with $10 \%$ fetal bovine serum (Gibco, Grand Island, NY, USA). The human liver hepatocellular carcinoma HepG2 cell line was cultured in DMEM (HyClone, Logan, UT, USA) supplemented with $10 \%$ fetal bovine serum (HyClone, Logan, UT, USA). The human prostate epithelial cell line RWPE-1 was maintained in Keratinocyte1 medium (K-SFM) supplemented with $50 \mathrm{mg} / \mathrm{L}$ bovine pituitary extract and $5 \mu \mathrm{g} / \mathrm{L}$ epidermal growth factor (Gibco, Grand Island, NY, USA). The cells were maintained in a humidified incubator with $5 \% \mathrm{CO}_{2}$ at $37^{\circ} \mathrm{C}$.

JA and JB were isolated from the Chinese liverworts Jungermannia fauriana. They were prepared in dimethyl sulfoxide (DMSO) at $10 \mathrm{mmol} / \mathrm{L}$ as stock solutions, stored at $-20^{\circ} \mathrm{C}$ and diluted according to experimental requirements.

Cell proliferation and cell cycle assay

To dynamically determine cell proliferation, PC3 cells were seeded at 4000 cells/well in microplates (Roche, Basel, Swiss) and were exposed to JA, JB, or vehicle. Cell growth curves were obtained by using the Real-Time Cell Analyzer SP Instrument (Roche, Basel, Swiss). Cell Index (CI) values were normalized at the time point at which the chemicals were added.

The MTT [3-(4,5-dimethylthiazol-2-yl)-2,5-diphenyl-2H-tetrazolium bromide, (Sigma, St Louis, MO, USA) colorimetric assay was also used to measure the proliferation of cells treated with JA and JB. The cells were propagated in 96-well culture plates at approximately $50 \%-70 \%$ confluence, and then the cells were treated with vehicle, JA or JB for a further $24 \mathrm{~h}$. The treated cells were incubated with $10 \mu \mathrm{L}$ of MTT (5 $\mathrm{mg} / \mathrm{mL}$ ) for $4 \mathrm{~h}$. The cell growth response to the chemicals was detected by measuring the absorbance at $570 \mathrm{~nm}$ on a plate reader (Bio-Rad, Calif, USA). All of the experiments were conducted at least three times.

To determine the changes in the cell cycle, PC3 cells were seeded in 6-well plates and treated with JA or JB for $24 \mathrm{~h}$. Vehicle treatment served as the control. After treatments, the cells were collected, fixed in iced $70 \% \mathrm{EtOH}$, and incubated with RNase (Invitrogen, Calif, USA) for $30 \mathrm{~min}$ at $37^{\circ} \mathrm{C}$. Next, the treated cells were exposed to propidium iodide (PI) (Sigma, St Louis, MO) for $30 \mathrm{~min}$ at $4^{\circ} \mathrm{C}$ in the dark. The cellular DNA content was analyzed by flow cytometry (Becton Dickinson, NJ, USA). The data were analyzed using MODFIT and CELLQUEST software (Verity Software House, Topsham, Maine, USA).

\section{Cell apoptosis assay}

PC3 cells were seeded in 6-well plates overnight. After treatment with JA $(1.5 \mu \mathrm{mol} / \mathrm{L})$ and JB $(5 \mu \mathrm{mol} / \mathrm{L})$ for the indicated time points, the cells were collected and incubated in Annexin V-FITC/PI staining solution according to the manufacturer's instructions (Becton Dickinson, NJ, USA). Apoptotic cells were analyzed using MODFIT and CELLQUEST software (Verity Software House, Topsham, Maine, USA).

\section{Western blotting}

Whole cell lysates were prepared using RIPA buffer containing a fresh protease inhibitor mixture $(0.5 \mathrm{mmol} / \mathrm{L}$ phenylmethanesulfonyl fluoride (PMSF), $50 \mu \mathrm{g} / \mathrm{mL}$ aprotinin, $10 \mathrm{mmol} / \mathrm{L}$ glycerol phosphate, $1 \mathrm{mmol} / \mathrm{L}$ sodium orthovanadate, 10 $\mathrm{mmol} / \mathrm{L} \mathrm{NaF}$ ). Proteins were quantified using the BCA protein assay (Beyotime Institute of Biotechnology, Shanghai, China). Samples containing equal amounts of proteins $(60 \mu \mathrm{g})$ from lysates were separated by SDS-PAGE and electrophoretically transferred to a nitrocellulose membrane (GE Healthcare, CT, USA). After being blocked with $5 \%$ non-fat milk in TBS buffer (20 mmol/L Tris- $\mathrm{HCl}, 137 \mathrm{mmol} / \mathrm{L} \mathrm{NaCl}, \mathrm{pH}$ 8.0) for $1 \mathrm{~h}$ at room temperature, the membrane was immunoblotted with specific primary antibodies at $4{ }^{\circ} \mathrm{C}$ overnight, was subjected to washing, and was incubated with HRP-conjugated secondary antibodies. Immunoblot bands were visualized using an enhanced chemiluminescence detection system (Millipore, DT, Germany) and exposed to X-ray films. 


\section{ROS measurement}

ROS accumulation was monitored using the fluorescent dye hydroethidine $2^{\prime}, 7^{\prime}$-dichlorodihydrofluorescein diacetate (DCFH-DA, Molecular Probes, Sigma-Aldrich, St Louis, MO, USA). After treatment with JA or JB for the indicated time points, cells were incubated with $10 \mu \mathrm{mol} / \mathrm{L}$ DCFH-DA at $37^{\circ} \mathrm{C}$ for $30 \mathrm{~min}$. The cells were then resuspended in PBS buffer and subjected to analysis immediately using flow cytometry (Becton Dickinson, NJ, USA).

\section{Transmission electron microscopy}

After treatment with JA or JB, PC3 cells were fixed with 2.5\% glutaraldehyde in $0.1 \mathrm{mmol} / \mathrm{L}$ PBS buffer ( $\mathrm{pH} 7.4$ ). The cells were washed with PBS buffer, incubated with $1 \%$ osmium tetroxide, followed by a dehydration series, and embedded in epon resin. The ultrathin sections were then cut and stained with 2\% uranyl acetate. A JEM-1400 transmission electron microscope (JEOL, Tokyo, Japan) was used to analyze changes in the cellular ultrastructure.

\section{Neutral comet assay}

PC3 cells were incubated with JA or JB for the indicated times. DNA damage was detected using the Trevigen's Comet Assay ${ }^{\circledR}$ Single Cell Gel Electrophoresis Assay (Trevigen, NIH, USA). Comet tails were imaged with a phase-fluorescence microscope (Nikon, Tokyo, Japan) and quantitated with Casp software. A minimum of 50 cells were scored per treatment.

\section{Statistical analysis}

The data are presented as the mean $\pm S D$ of at least three independent experiments. The statistical significance of the mean differences between the control and treated groups was determined with two-tailed Student's $t$-tests. Multiple group comparisons were performed with one-way ANOVAs, followed by Dunnett's multiple comparison test. For all tests, a $P$ value less than 0.05 was considered to be statistically significant.

\section{Results}

\section{JA and JB inhibit cell proliferation and induce apoptosis}

The screening assay of 44 naturally occurring diterpenoids previously led us to the identification of JA and JB as chemicals that potentially inhibit cancer cell proliferation ${ }^{[21]}$. Here, we extended our observations to determine the inhibitory effects of JA and JB on a panel of cancer cell lines and the human non-neoplastic prostate epithelial cell line RWPE-1. As shown in Table 1, JA and JB both chemicals exhibited strong anti-proliferative effects on many cancer cells with $\mathrm{IC}_{50}$ values of 1-8 $\mathrm{mmol} / \mathrm{L}$, except for MCF-7, with higher $\mathrm{IC}_{50}$ values of 18.29 and $14.18 \mu \mathrm{mol} / \mathrm{L}$ for JA and JB, respectively. All of the tested PCa cell lines showed good responses to both JA and JB, and non-neoplastic prostate epithelial RWPE1 cells were more resistant to the treatments with higher $\mathrm{IC}_{50}$ values, compared with PC3 cells (Table 1). Because PC3 cells were more sensitive to both compounds, this led us to the selection of PC3 cells, which lack functional p53 and are somewhat resistant to apoptosis $^{[22]}$, as a model for further mechanistic studies.
Table 1. Cytotoxic activity of ent-kaurane diterpenoids. Values are the mean $\pm S D$ of three experiments.

\begin{tabular}{lrr}
\hline Cell lines & \multicolumn{2}{c}{$\mathrm{IC}_{50}(\mu \mathrm{mol} / \mathrm{L})$} \\
& \multicolumn{1}{c}{$\mathrm{JA}$} \\
\hline PC3 & $1.34 \pm 0.09$ & $4.93 \pm 0.20$ \\
DU145 & $5.01 \pm 0.27$ & $5.50 \pm 0.16$ \\
LNCaP & $2.78 \pm 0.02$ & $3.18 \pm 0.11$ \\
K562 & $2.22 \pm 0.01$ & $1.93 \pm 0.08$ \\
A549 & $8.64 \pm 0.49$ & $5.26 \pm 0.54$ \\
NCl-H1299 & $2.56 \pm 0.05$ & $2.44 \pm 0.06$ \\
NCl-H446 & $1.23 \pm 0.06$ & $7.91 \pm 0.16$ \\
MCF-7 & $18.29 \pm 1.02$ & $14.18 \pm 0.57$ \\
HepG2 & $5.29 \pm 0.17$ & $6.02 \pm 0.28$ \\
RWPE1 & $5.09 \pm 0.14$ & $18.18 \pm 3.61$ \\
\hline
\end{tabular}

We monitored the cell growth in response to the treatments with a Real-Time Cell Analyzer SP Instrument. The results in Figure 1B revealed that either JA or JB time-dependently reduced the viability of cells, and the effect of JA was more rapid and evident at lower concentrations compared with that of JB, thus suggesting that JA was more potent in affecting PC3 cell proliferation. Cell shrinkage was observed after treatments (Figure 1C), thus suggesting that the apoptosis was induced by both JA and JB. We were prompted to analyze the apoptotic cells exposed to JA and JB by flow cytometry. The results in Figure 1D demonstrated that JA caused significant increases in the fraction of apoptotic cells, showing $5.34 \%$ of apoptotic cells at $0 \mathrm{~h}$, and up to $30.11 \%$ after 24 -h treatment. Similarly, the apoptotic cell fractions in response to JB were $5.41 \%$ and $31.47 \%$, respectively, under the same conditions. In addition, the activation of caspase 3 and an increase in the cleavage of poly ADP-ribose polymerase (PARP), two hallmarks of apoptosis ${ }^{[8]}$, were clearly noticeable in cells exposed to either JA or JB (Figure 1E), thus suggesting that JA and JB promoted apoptosis in a time-dependent manner. Z-VAD, a caspase family inhibitor, was included to confirm the ability of JA and JB that induced caspase-dependent cell apoptosis. The results showed that Z-VAD markedly rescued cell death induced by each of compounds (Figure 1F). Thus, both JA and JB were capable of inhibiting cell proliferation and triggering caspase-dependent apoptosis.

Induction of ROS by JA and JB contributes to their effect on apoptosis via mitochondrial damage and DNA damage

Because intracellular ROS levels were increased in cells treated with other ent-kaurane-type diterpenoids ${ }^{[23,24]}$, we also sought to examine the ability of JA and JB to induce ROS. As shown in Figure 2A, a rapid and significant increase in ROS was observed in PC3 cells after a 2-h treatment with JA, and the high level of ROS was sustained during the prolonged treatment period. Elevated ROS was also markedly accumulated in JB-treated cells at $2 \mathrm{~h}$, was maintained up to $12 \mathrm{~h}$, and followed by a slight decrease after 24-h treatment (Figure 2A). Notably, the time course of ROS production upon treatment 
A

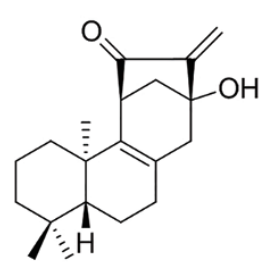

JA

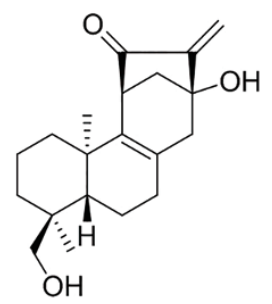

JB

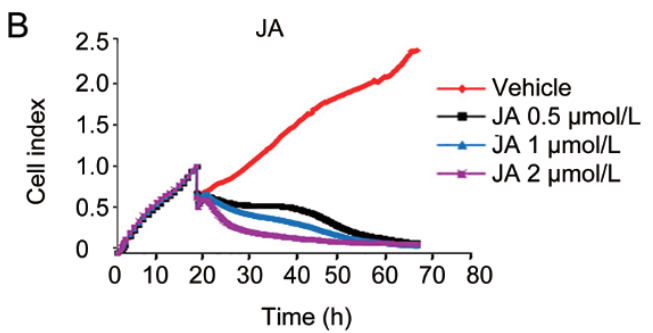

C

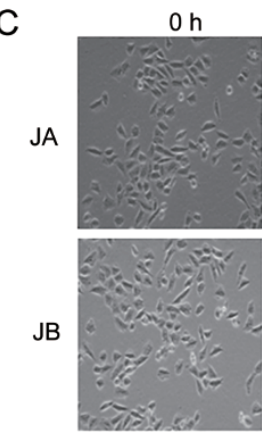

$2 \mathrm{~h}$
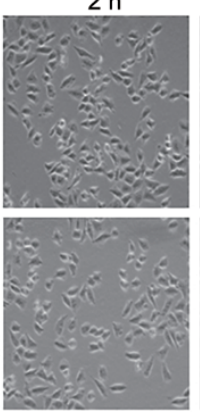

$4 \mathrm{~h}$
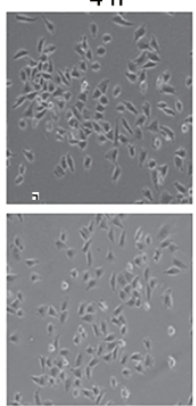

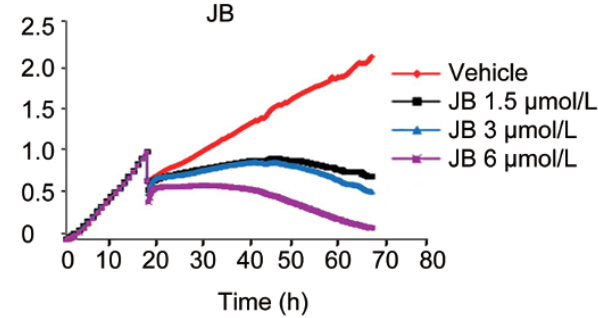

$8 \mathrm{~h}$
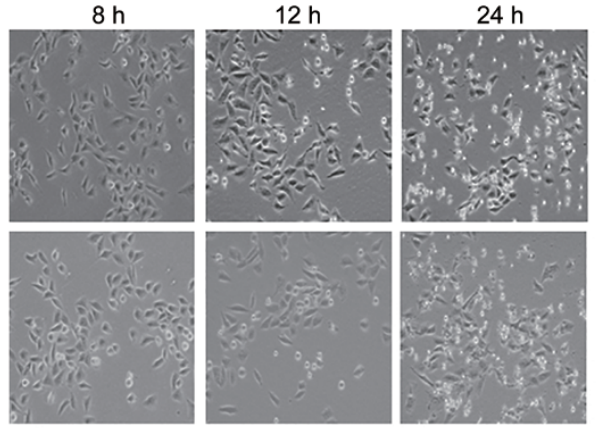

D
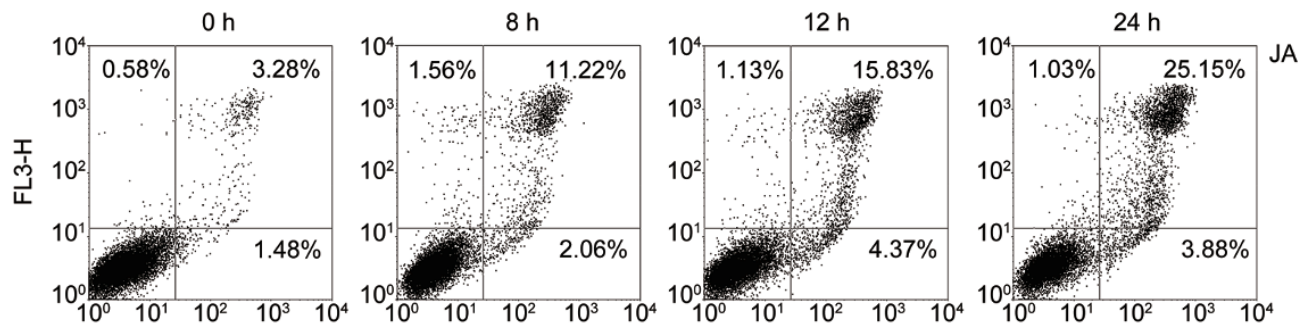

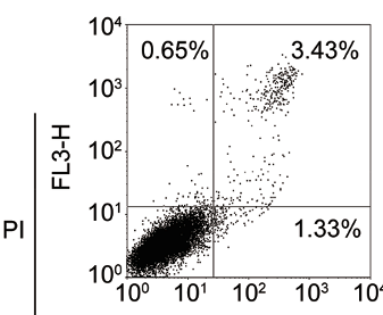

Annexin V
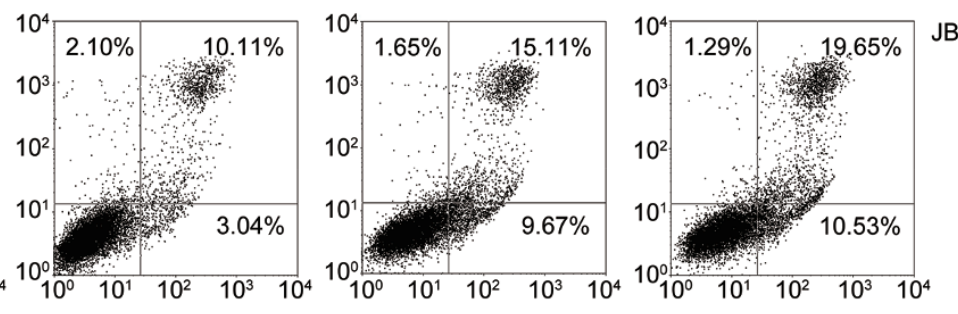

FL1-H

E

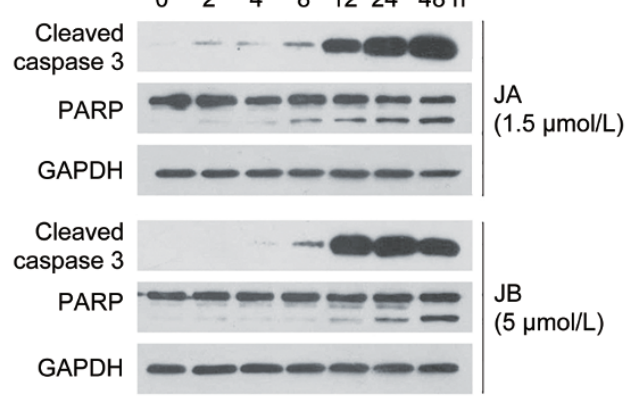

F

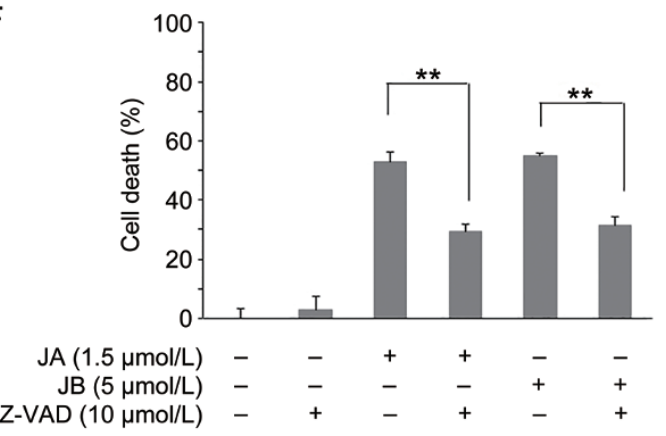

Figure 1. Effects of JA or JB on cell proliferation and apoptosis in PC3 cells. (A) The chemical structures of JA and JB. (B) Cell proliferation in response to JA and JB was monitored by the cell index $(\mathrm{Cl})$ values using $x \mathrm{CEL}$ Ligence System. (C) Cellular morphology changes after $1.5 \mu \mathrm{mol} / \mathrm{L} \mathrm{JA}$ and $5 \mu \mathrm{mol} / \mathrm{L}$ JB treatment were observed by microscope. (D) PC3 cells were treated with $1.5 \mu \mathrm{mol} / \mathrm{L} \mathrm{JA}$ or $5 \mu \mathrm{mol} / \mathrm{L} \mathrm{JB}$ for the indicated times. Cells were collected and stained with FITC-conjugated annexin V and PI and immediately subjected to flow cytometry. (E) The expression of cleaved caspase-3 and PARP were assayed by Western blotting in cells treated with JA or JB for the indicated times. GAPDH served as the loading control. (F) Cytotoxic effects of JA and JB alone or combined with Z-VAD $(10 \mu \mathrm{mol} / \mathrm{L})$ in PC3 cells over $24 \mathrm{~h}$ were measured by MTT assay. All values are expressed as the means \pm SD of three independent experiments. ${ }^{* *} P<0.01$ compared to the untreated control group. 

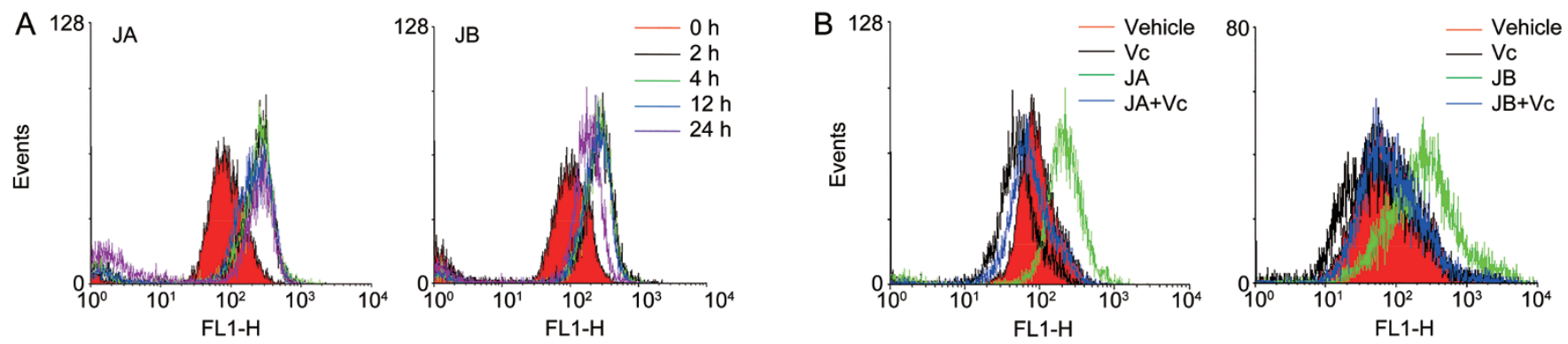

C
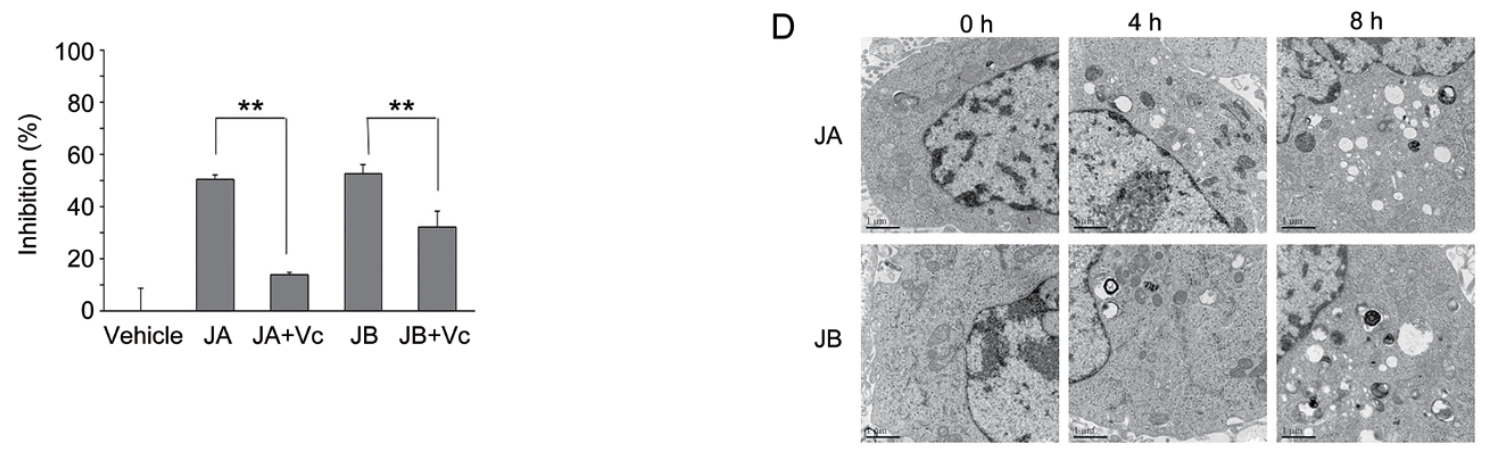

E

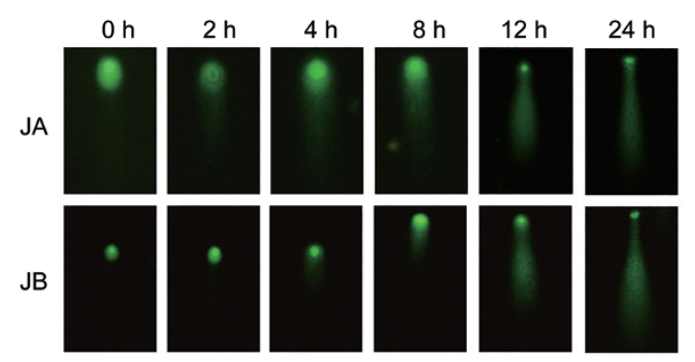

F
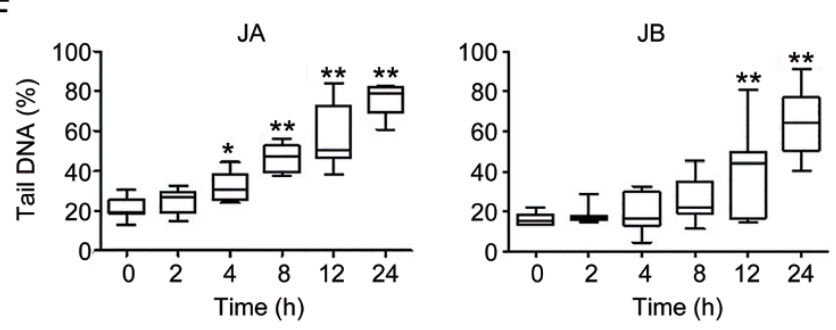

G

$\begin{array}{llllllll}0 & 2 & 4 & 8 & 12 & 24 & 48 & h\end{array}$

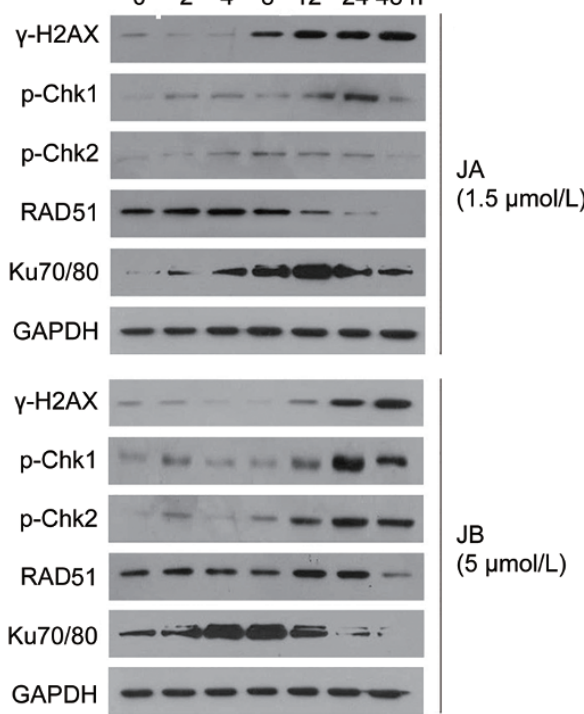

$\mathrm{H}$

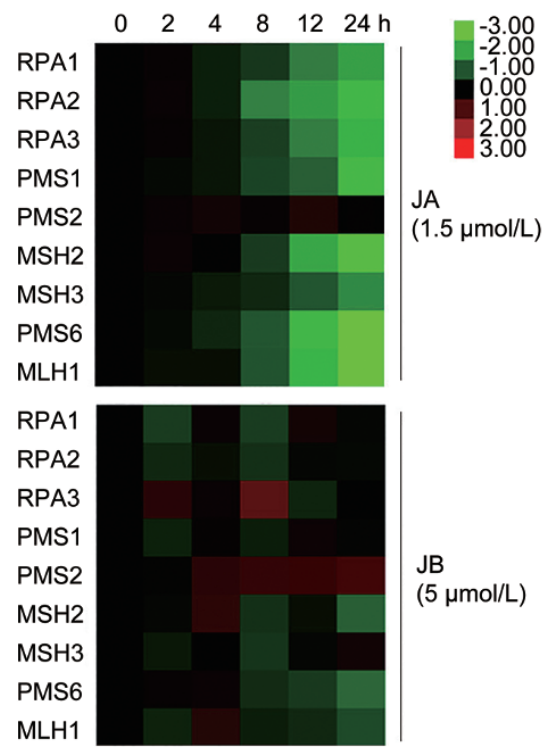

Figure 2. Effects of JA and JB on the generation of ROS, mitochondrial and DNA damage induction in PC3 cells. (A) PC3 cells exposed to $1.5 \mu$ mol/L JA or $5 \mu \mathrm{mol} / \mathrm{L} \mathrm{JB}$ for the indicated times were collected, stained with DCFH-DA, and detected by flow cytometry. (B) PC3 cells were treated with vitamin $\mathrm{C}(0.5 \mu \mathrm{mol} / \mathrm{L}) 2 \mathrm{~h}$ before JA and JB added. (C) Cytotoxic effects of JA and JB alone or combined with vitamin C in PC3 cells over $24 \mathrm{~h}$ as measured by MTT assay. (D) Electron micrographs show mitochondria damage induced by JA or JB. PC3 cells were treated with JB or JB for different time. (E) Neutral comet assay was performed to determine DNA fragment in JA or JB treated cells. (F) Distribution of mean comet length (50 cells per sample) was calculated by box and whisker plot. Medians are indicated by cross; interquartile range (25\%-75\%; IQRs) are indicated by open boxes. The whiskers are 1.5 times the IQR distribution. (G) Western blot analysis of Y-H2AX, RAD51, Ku70/80, phospho-chk1 (Ser296) and phospho-chk2 (Thr68) protein levels in whole cell lysates from PC3 cells treated with indicated chemicals. (H) Heatmap for mRNA levels of DNA repair genes in JA or JB treated cells was determined by real-time RT-PCR. Red: up-expression, green: down-expression, black: unchanged expression. ${ }^{*} P<0.05,{ }^{* *} P<0.01$ compared to the untreated control group. 
with each of the agents matched the activation of caspase 3 (Figure 1E), thus indicating that the induction of ROS might be a required signal for chemical-mediated apoptosis. We then introduced vitamin $\mathrm{C}(\mathrm{Vc})$ to block ROS and then investigated the role of ROS in chemical-mediated cell death. As shown in Figure 2B, Vc prevented JA- or JB-induced ROS. Importantly, the JA-triggered inhibitory effect was markedly reversed by $\mathrm{Vc}$, from $50.14 \%$ to $13.65 \%$ (Figure $2 \mathrm{C}$ ), thus highlighting the importance of ROS in JA-mediated cytotoxicity. Similar observations were also found in JB-treated cells, in which the inhibitory effect of JB was rescued from $52.64 \%$ to $31.98 \%$ in the presence of $\mathrm{Vc}$ (Figure 2C). Given the relevance of ROS production in mitochondria, the change in the structure of mitochondria by JA and JB was examined by transmission electron microscopy. The results clearly revealed that both JA and JB caused dramatic mitochondrial swelling, leading to disorganized cristae and vacuolar structure (Figure 2D). We further investigated whether DNA damage occurred in cells in response to JA and JB because of high levels of ROS. The neutral comet assay indicated that a DNA tail was detectable after a 4-h treatment with JA, or a 12-h treatment with $\mathrm{JB}$ and became more pronounced with prolonged treatments (Figure 2E, 2F). These results were consistent with the above observations that JA was more potent than JB because DNA damage occurred earlier in JA-treated cells. Correspondingly, the results in Figure $2 \mathrm{G}$ provided additional evidence that the phosphorylation of $\mathrm{H} 2 \mathrm{AX}$ at $\operatorname{Ser}^{139}(\mathrm{\gamma H} 2 \mathrm{AX})$, a marker of DNA strand breaks, was clearly present at $8 \mathrm{~h}$ after JA treatment and lasted at high levels up to $48 \mathrm{~h}$. The level of DNA damage was similar in JB-treated cells but was delayed until $12 \mathrm{~h}$. The data indicated that JA and JB significantly cause DNA damage in PC 3 cells. We then examined changes in Chk1/2, critical factors mediating the ATM/ATR signaling pathways, which are activated after DNA damage. Kinetic studies showed that in response to JA-induced DNA damage, phospho-Chk2 $\left(\mathrm{Thr}^{68}\right)$ was slightly increased at $2 \mathrm{~h}$ and lasted during the treatment period, matching the time points of DNA damage induction, whereas the activation of Chk1 $\left(\mathrm{Ser}^{296}\right)$ was more evident with 12-h and 24-h treatments with JA compared with that of Chk2 (Figure 2G). In the case of JB, activation of Chk1 and Chk2 was pronounced after 12-h exposure to JB (Figure 2G). These results indicated a consequence of a persistent DNA damage response in the presence of the two chemicals.

Because the DNA damage response leads to the recruitment of repair proteins and enzymes at the breaks, we further investigated whether JA and JB affected DNA damage repair. The results in Figure 2G indicated that after 2-h exposure of the cells to each of the chemicals, Ku70/Ku80 expression, which is important in DNA double-strand lesion repair, displayed an increase at $2 \mathrm{~h}$ and was sustained up to $12 \mathrm{~h}$ in response to JA or to $8 \mathrm{~h}$ in cells exposed to JB, and then significantly declined after prolonged treatment. Additionally, the levels of RAD51, another DNA repair protein, were decreased after prolonged treatment with JA and JB (Figure 2G). Moreover, we confirmed the inhibitory effect of JA and JB on gene expression associated with DNA damage repair by qPCR. As shown in Figure $2 \mathrm{H}$, JA treatment significantly suppressed the expression levels of RPA1/2/3, PMS1/2, MSH2/3, PMS6 and MLH1, genes essential for DNA replication and repair. However, JB inhibited most of the genes tested, except PMS2, and transiently activated RPA3, MSH2, and MLH1, thus suggesting that alternative mechanisms might be involved in the JBinduced DNA damage response. Together, the pattern of the cellular responses to JA or JB indicated that the compounds initiated ROS production, which in turn led to the induction of mitochondrial damage and persistent DNA damage.

\section{The DNA damage response and activation of checkpoints by JA and JB contribute to cell cycle arrest}

In response to DNA damage, cells activate a signaling network to arrest the cell cycle and facilitate DNA repair, thus leading to cell proliferation inhibition and apoptosis if DNA repair has failed ${ }^{[25]}$. According to the observations above, we reasoned that JA and JB affect the cell cycle. As indicated by flow cytometry, as displayed in Figure 3A, the treatment of cells with JA caused a dose-dependent accumulation of cells in the $G_{0} / G_{1}$ phase and a corresponding decrease in the $S$ and $G_{2} / M$-phase fractions. As summarized in Figure 3B, the cells in the $\mathrm{G}_{0} / \mathrm{G}_{1}$ phase increased by $56.74 \%, 69.63 \%$, and $76.67 \%$ at the concentrations of $0,0.75$, and $1.5 \mu \mathrm{mol} / \mathrm{L}$ of JA, respectively. These changes correlated with the decreased populations in $\mathrm{S}$ of $31.03 \%, 18.28 \%$, and $12.67 \%$, and in $\mathrm{G}_{2} / \mathrm{M}$ of $12.23 \%, 12.09 \%$ and $10.66 \%$, respectively. However, unlike JA, JB treatment caused a dose-dependent accumulation of cells in the $G_{2} / M$ phase: the increased numbers of cells in the $\mathrm{G}_{2} / \mathrm{M}$ phase were $10.58 \%, 13.58 \%$, and $27.66 \%$ at treatment concentrations of $0,2.5$, and $5 \mu \mathrm{mol} / \mathrm{L}$ of JB, respectively; a decrease in the $S$ phase fraction was also observed (Figure 3A, 3B). A similar effect of JA and JB on cell cycle progression was observed in the DU145 cell line, another typical PCa cell line (data not shown); however, the magnitude of the increase was less than that in PC 3 cells.

Because PC3 cells lack functional p53 protein, we assessed the changes in other key modulators that play important roles in cell cycle progression after treatments. As clearly shown in Figure 3C both Cyclin D1 and E were time-dependently reduced after treatment with JA. Activation of cyclin-dependent kinase 4 (CDK4) is essential to facilitate the cell cycle via its association with Cyclin D1. JA also caused a noticeable decrease in the levels of CDK4 starting at $8 \mathrm{~h}$, correlating with reduced Cyclin D1 (Figure 3C). Meanwhile, p21 ${ }^{\mathrm{CIP} 1}$, an important cyclin-dependent kinase inhibitor, was up-regulated after a 4-h treatment with JA. Notably, the levels of Cyclin B1, a critical regulatory modulator in the $\mathrm{G}_{2} / \mathrm{M}$ phase of cell cycle progression, were relatively unchanged in response to JA (Figure $3 \mathrm{C}$ ). Alterations in cell cycle regulators favored cell cycle block in the $G_{0} / G_{1}$ phase by JA, a finding consistent with the results of the flow cytometry assays (Figure $3 \mathrm{~A}, 3 \mathrm{~B}$ ). Interestingly, prolonged exposure to JA (12 $\mathrm{h}$ and thereafter) led to a decrease in phosphorylated Cdc2 (also known as Cdk1, the inactive form of Cdc2) (Figure 3C). It has been reported that the activation of Cdk1 plays a role in apoptosis that is inde- 
A
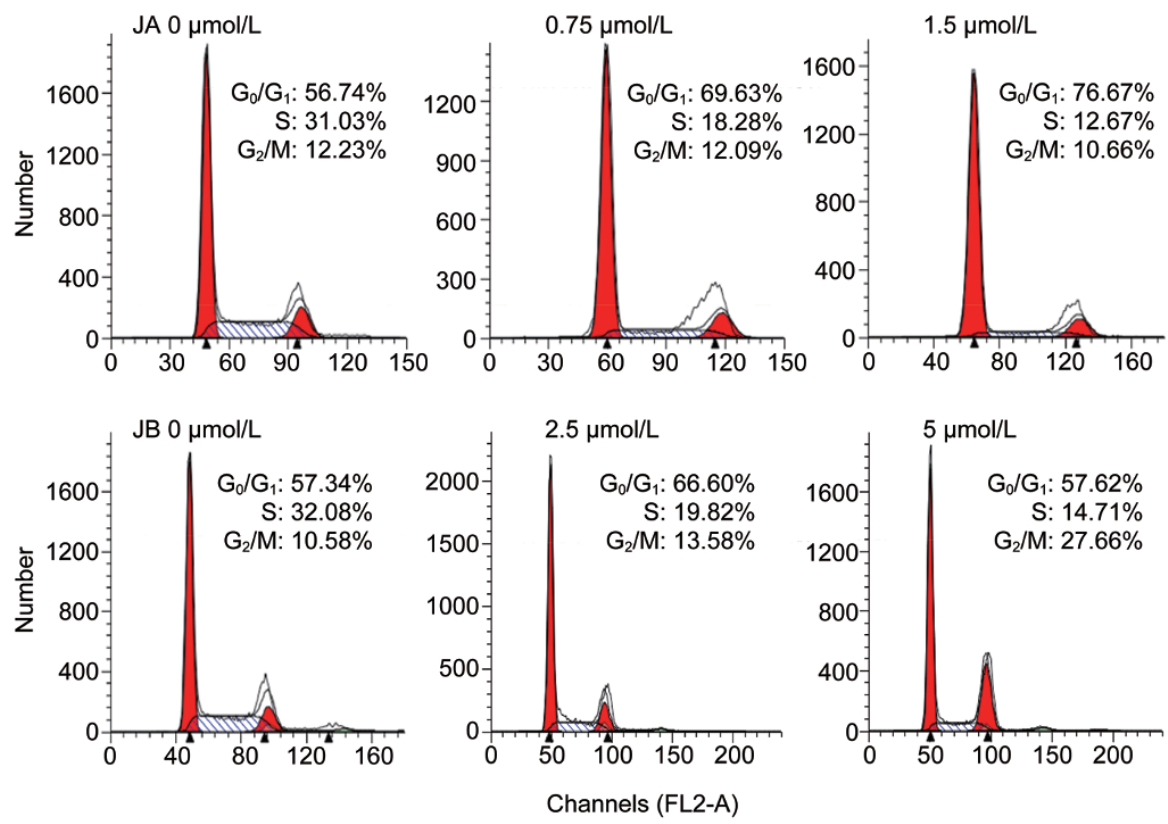

C

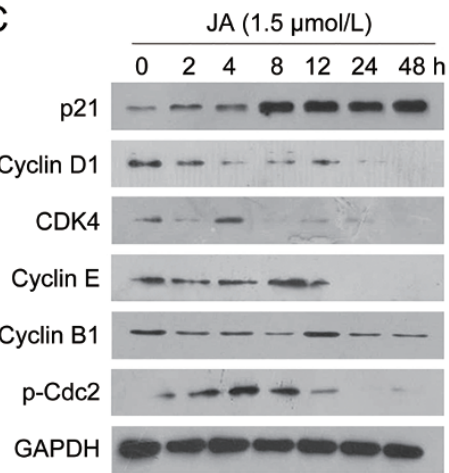

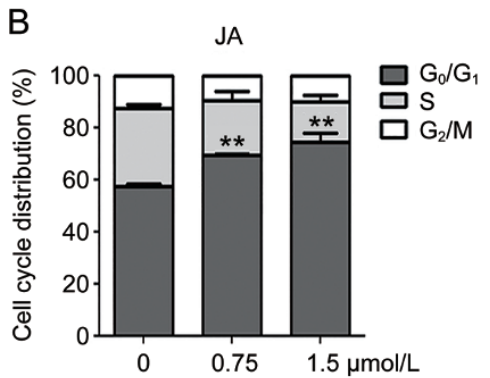

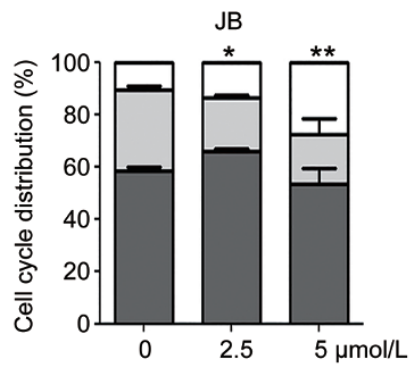

Figure 3. JA and JB induce PC3 cell cycle arrest. (A) After exposure of PC3 cells to JA (0, $0.75,1.5 \mu \mathrm{mol} / \mathrm{L})$ or JB $(0,2.5,5 \mu \mathrm{mol} / \mathrm{L})$ for $24 \mathrm{~h}, \mathrm{cells}$ were harvested, stained with propidium iodide, and the cell cycle was analyzed by flow cytometry. Flow cytometric histograms are representative of three separate experiments. (B) Quantitative analyses of percent gated cells at the $G_{0} / G_{1}, S$, and $G_{2} / M$ phases were shown. All values are expressed as the means \pm SD of three independent experiments. (C) The levels of cyclin B1, phospho-Cdc2 (Tyr15), CDK4, cyclin D1, cyclin E, and p21 ${ }^{\mathrm{CIP} 1}$ in PC3 cells were measured by Western blotting with GAPDH as the loading control. ${ }^{*} P<0.05,{ }^{* *} P<0.01$ compared to the untreated control group.

pendent of its role in cell cycle progression ${ }^{[26]}$. Compared with JA treatment, JB treatment induced strong $\mathrm{G}_{2} / \mathrm{M}$ arrest in PC3 cells; the results in Figure $3 \mathrm{C}$ revealed that the levels of Cyclin B1 and phospho-Cdc2 predominantly declined after treatment with JB in a time-dependent manner, and almost no changes in Cyclin D1 and CDK4 were observed until the end of the treatments. In line with JA exposure, the exposure of cells to $\mathrm{JB}$ also predominantly induced the expression of $\mathrm{p} 21^{\mathrm{CIP1}}$ (Figure 3C). Thus, these chemical-induced perturbations of cell cycle progression demonstrated the different patterns of cellular responses by the two agents: JA caused $\mathrm{G}_{0} / \mathrm{G}_{1}$ phase arrest, whereas JB induced persistent $\mathrm{G}_{2} / \mathrm{M}$ blockage.

The suppression of c-Myc and the activation of JNK are required for the blockade of the cell cycle by JA and JB

To better understand the cellular basis of the different cell cycle responses activated by the two agents, we first studied the PI3K/AKT signaling pathway, which is constitutively activated and is critical for PC3 cell survival ${ }^{[27,28]}$. Exposure of cells to JA resulted in the inactivation of Akt at $4 \mathrm{~h}$, and a pronounced decrease in phospho-Akt was observed after prolonged treatments (Figure 4A), whereas no considerable change in phospho-Akt was observed after JB treatment. The results suggested that the inhibition of the Akt pathway was, at least in part, an event in JA-mediated cell death but might not be critical for the effect of JB. It is believed that in the absence of p53, cells depend on a third cell-cycle checkpoint pathway or modulators, such as the MAPK signaling pathways, MK2, and c-Myc, for cell cycle arrest and survival after DNA damage ${ }^{[29,30]}$. As shown in Figure 4A, the levels of phospho-p38 remained nearly unchanged after treatment with either agent, thus indicating that the p38 pathway might not 
A

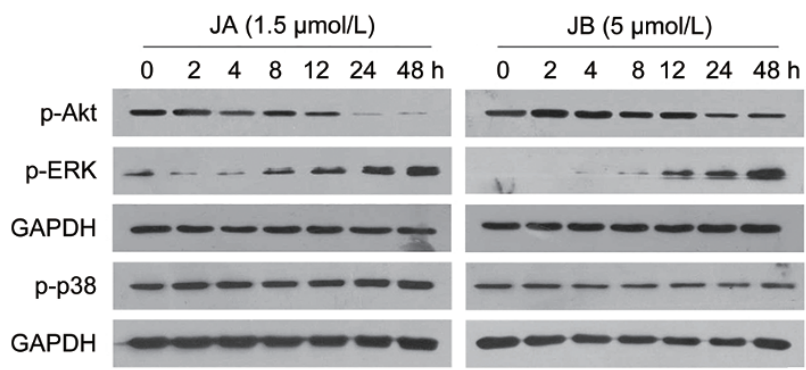

C

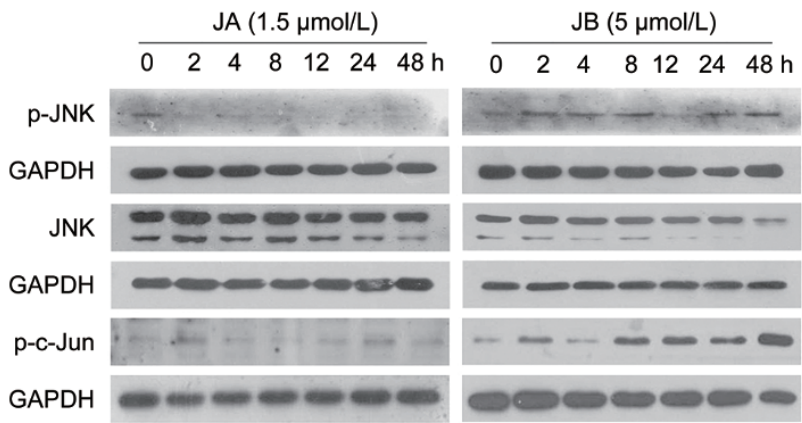

B

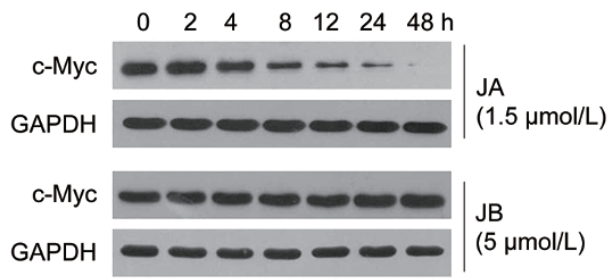

D

Nci ++-
JNK1/2i -+
Vehicle +-+
JB -+-

$(5 \mu \mathrm{mol} / \mathrm{L})$

JNK $-21-\cdots$

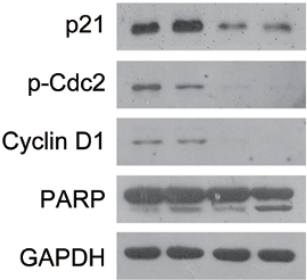

F

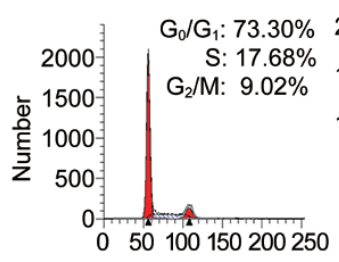

$\begin{array}{rr}\text { Nci } & + \\ \text { JNK1/2i } & - \\ \text { Vehicle } & + \\ \text { JB } & -\end{array}$

(5 $\mu \mathrm{mol} / \mathrm{L})$

G

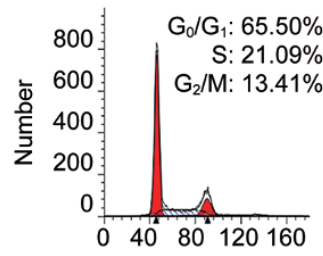

$$
\begin{array}{r}
\text { pcDNA3.1 } \\
\text { c-Myc } \\
\text { Vehicle }
\end{array}
$$

JA

$(1.5 \mu \mathrm{mol} / \mathrm{L})$

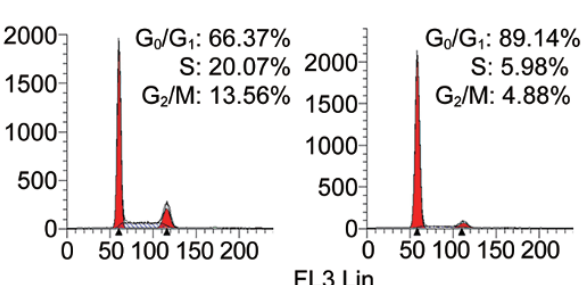

FL3 Lin

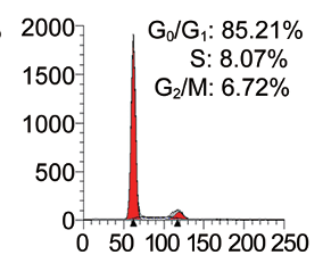

-
+
+

Figure 4. JA and JB induced cell cycle arrest at different phases through two pathways. (A) Effects of JA or JB on the expression of phospho-AKT (Ser473), phospho-ERK (Tyr202/Tyr204) and phospho-p38 (Thr180/Tyr182) in PC3 cells were estimated in whole cell lysates by Western blot analysis. GAPDH served as an internal control to monitor protein loading and transferring efficiency. (B) Effects of JA or JB on the expression of C-Myc in PC3 cells was estimated in whole cell lysates by Western blot analysis. (C) Effect of JA or JB on the expression of JNK, phospho-JNK (Tyr15) and phospho-CJun (Tyr15) in PC3 cells were estimated in whole cell lysates by Western blot analysis. GAPDH served as an internal control to monitor protein loading and transferring efficiency. (D) Impact of JNK knockdown on p21, p-Cdc2, cyclin D1 and PARP expression of JB-treated PC3 cells. JB treatment was performed $24 \mathrm{~h}$ following siRNA transfection. (E) Impact of c-Myc over-expression on the p21, cyclin D1, CDK4 and PARP expression of JA-treated PC3 cells. JA treatment was performed $24 \mathrm{~h}$ following plasmid transfection. $(\mathrm{F}, \mathrm{G})$ Impact of JNK knockdown or c-Myc over-expression on the cell cycle distribution in JB- or JA-treated PC3 cells. The silencing efficiency and expression of modulators associated with the $\mathrm{G}_{2} / \mathrm{M}$ phase were examined using Western blotting. The over-expressing efficiency and expression of modulators associated with the $G_{0} / G_{1}$ phase were examined using Western blotting. All values are expressed as the means \pm SD of three independent experiments. ${ }^{*} P<0.05,{ }^{* *} P<0.01$ compared to the untreated control group. 
contribute to cell cycle arrest. We next evaluated the changes in ERK and JNK in response to JA or JB. As shown in Figure $4 \mathrm{~A}$, in the time-kinetics study, the activation of ERK was evident in cells exposed to both compounds, thus suggesting that the ERK pathway is not required for the different responses of cell cycle arrest. A minimal decrease in the total JNK protein level was observed after prolonged exposure to the two agents. However, Figure $4 \mathrm{C}$ revealed that the phospho-JNK level was up-regulated starting from 2 to $48 \mathrm{~h}$ in JB-treated cells. Accordingly, the activation of c-Jun, a downstream target of JNK, was also evident after JB treatment from 2 to 48 $h$. In contrast, we did not observe any considerable change in phospho-JNK and phospho-c-Jun with JA treatment. The data prompted us to investigate whether the JNK pathway, one of the major signaling pathways activated by oxidative stress, is involved in the regulation of the cell cycle and survival by JB. As shown in Figure 4F, knockdown of the endogenous expression of JNK1/2 by JNK1/2-targeting siRNA significantly disrupted the $\mathrm{G}_{2} / \mathrm{M}$ phase blockade induced by JB, thus indicating the importance of JNK in JB-mediated cell cycle arrest. Western blot analysis further verified that the levels of p21 ${ }^{\mathrm{CIP} 1}$, Cyclin D1 and phospho-Cdc2 were decreased in JNK1/2silenced cells, and this was accompanied by cell cycle arrest in the $\mathrm{G}_{0} / \mathrm{G}_{1}$ phase. The cleavage of PARP, a marker of apoptotic cells, was more pronounced (Figure 4D), thus indicating that the activation of JNK by JB, at least in part, was essential for the $\mathrm{G}_{2} / \mathrm{M}$ blockade.

We next sought to determine which factors might underlie the regulation of the $G_{0} / G_{1}$ cell cycle arrest by JA because no major changes in distinct cell signaling pathways were displayed in JA-treated cells. Given the effect of c-Myc on the regulation of cell cycle progression and that the protein is highly expressed in PCa cells ${ }^{[31]}$, we tested the possibility that c-Myc might be involved in JA-mediated cell cycle arrest. As shown in Figure 4B, the protein level of c-Myc was significantly decreased after 4-h treatment with JA, and more prominently thereafter, whereas c-Myc remained unchanged in cells exposed to JB. We performed rescue experiments to increase the abundance of c-Myc in cells transfected with a c-Myc plasmid to determine the role of c-Myc in JA-induced cell cycle arrest. The results showed that the cell number in the $G_{0} / G_{1}$ phase was $78.71 \%$ in response to JA and that in the $\mathrm{G}_{0} / \mathrm{G}_{1}$ phase decreased to $68.99 \%$ when the cells were transfected with c-Myc (Figure 4G), thus indicating that the overexpression of c-Myc resulted in the alleviation of the cells arrested in $G_{0} / G_{1}$ phase by JA. In addition, the forced expression of c-Myc dramatically reduced the level of $\mathrm{p} 21^{\mathrm{CIP} 1}$ and increased Cyclin D1 expression, leading to promotion of cell cycle progression and a decrease in apoptosis, as indicated by the observed loss of JA-induced cleaved PARP (Figure 4D). The data demonstrated that the different effects on the c-Myc protein and the JNK signal contributed to the JA- and JBmediated cell cycle blockade, respectively.

\section{Discussion}

Unchecked proliferative potential involving the deregulation of cell cycle progression is believed to be a central process in the development of cancer. Therefore, breaking the balance of cell cycle progression is an effective therapeutic target ${ }^{[32]}$. The findings of the present study demonstrated that JA and JB, two natural compounds present in Jungermannia fauriana, exerted strong anti-proliferative effects against several cancer cells, including PCa cells. However, no synergistic effect on cellular proliferation inhibition was observed when we combined the two compounds (data not shown). This effect involved alterations in cell cycle regulators, causing both $\mathrm{G}_{0} / \mathrm{G}_{1}$ and $\mathrm{G}_{2} / \mathrm{M}$ arrest as well as cell death. One of the plausible mechanisms accounting for these compounds' inhibitory activity occurred through the ROS-dependent mitochondrial and DNA damage responses, subsequently leading to cell cycle arrest. Failure in DNA repair by the two agents finally resulted in cellular apoptosis. Molecular studies showed that JA blocked cell cycle progression in the $G_{0} / G_{1}$ phase associated with the down-regulation of Cyclin E, D1 and CDK4, together with an increase in the CDK inhibitor $\mathrm{p} 21^{\mathrm{CIP1}}$. Suppression of the c-Myc protein level was critical for JA-induced $G_{0} / G_{1}$ arrest. The $G_{2} / M$ blockade by JB was accompanied by the reduction in the levels of Cyclin B1 and phospho-cdc2. Furthermore, the activation of the JNK pathway by JB contributed to the $\mathrm{G}_{2} / \mathrm{M}$ arrest. Our comparative study of these two agents indicated that: (a) JA had more potent effects on cell cycle arrest and cell death than JB because JA rapidly exerted its effects at lower concentrations than those of JB, and (b) cell cycle progression exhibited different responses to the two agents. Through analysis of the structure of JA and JB (Figure 1A), we observed that JB has an additional hydroxyl moiety at position 18 compared with JA, thus suggesting that JA is more hydrophobic, which may facilitate JA to cross the cellular membrane, enter cells and lead to a rapid change in the cell phenotype.

It has been reported that ent-kaurane diterpenoids exhibit cytotoxic effects with the induction of $\operatorname{ROS}^{[23,24,33]}$. Consistently with the observations that oridonin and longikaurin A induce ROS-dependent inhibitory effects on cell proliferation, our study demonstrated that both JA and JB induced ROS production, which in turn led to the DNA damage response. Extra ROS induce DNA damage in PC3 cells and inhibition of DNA repair causes DNA double-strand breaks (DSBs). Defects in DNA damage repair have been observed in PCa cells, resulting in malignant cells with a weak capacity for DNA repair ${ }^{[34]}$. In the present study, JA and JB treatments caused a DNA damage response and exhibited an extensive inhibitory effect on many DNA repair proteins/enzymes. The ATM/Chk2 and ATR/Chk1 pathways are well defined signaling pathways that respond to DNA damage ${ }^{[35]}$. As DNA damage sensors, ATM and ATR activate different downstream mediators with different contributions to cellular responses that determine cell cycle arrest, DNA repair or cell death. In response to JAinduced DNA damage, phospho-Chk2 slightly increased at simultaneously with DNA damage (Figure 2G), and activation of Chk1 was more evident compared with that of Chk2. Both JA and JB caused persistent activation of Chk1 and Chk2 (up to $24 \mathrm{~h}$ and $48 \mathrm{~h}$ ), although a stronger induction of phospho- 
Chk1 and phospho-Chk2 was observed in JB-treated cells. The response of Chk1 and Chk2 in cells suggested that apoptosis induced by JA and JB may be the result of persistent cell cycle arrest due to the defects in DNA repair in PC3 cells, as further supported by long-lasting H2AX phosphorylation after drug treatments. The $\mathrm{Ku}$ protein heterodimer $\mathrm{Ku} 70 / 80$, which is critical for the repair of dsDNA breaks ${ }^{[36]}$, was initially induced in response to DNA damage and was decreased after prolonged treatment by each agent, thus supporting the effect of the chemicals on the induction of the DNA damage response. In addition, JA and JB inhibited DNA repair, including the suppression of RPA proteins, which are involved in binding to single-stranded DNA to protect DNA lesions during DNA replication, recombination and repair ${ }^{[36,37]}$, and the suppression of mismatch repair proteins ${ }^{[38]}$ and recombinase RAD51, which are important in mediating homologous recombination $^{[39]}$. We also noted that the inhibitory effect of JB on repair proteins was less than that of JA, in agreement with the observations that JB induced delayed apoptosis and lower cytotoxic activity.

In response to these two agents, the MAPK signaling pathways appeared to be activated through the sensing of DNA damage. JNK is a stress-activated protein kinase that phosphorylates c-Jun at two sites in the $\mathrm{NH}_{2}$-terminal activation domain ${ }^{[40]}$. Phosphorylated c-Jun acts as a transcription factor modulating the expression of many genes that determine cell survival or death. For example, evodiamine ${ }^{[41]}$, a natural chemical isolated from Evodia rutaecarpa, has been reported to induce human colorectal carcinoma cell apoptosis and $\mathrm{G}_{2} / \mathrm{M}$ arrest through JNK activation, consistently with our observations that JB up-regulated the phosphorylation of JNK, leading to the blockade of PC3 cells in the $\mathrm{G}_{2} / \mathrm{M}$ phase. Notably, the suppression of c-Myc, but not the activation of stress kinases, played a critical role in cell cycle arrest in the $G_{0} / G_{1}$ phase in response to JA. It has been demonstrated that Sirt3 destabilizes c-Myc through the Akt pathway, and the inhibition of Akt is required to abrogate c-Myc expression ${ }^{[42]}$. We noted that JA predominantly inactivates Akt compared with that of JB; the decreased phospho-Akt was observed at $4 \mathrm{~h}$ and lasted during the treatment period. The level of c-Myc was correspondingly reduced in JA-treated cells. This finding suggested that the suppression of c-Myc by JA might be a result of Akt inactivation. Further study is required to address whether JA inhibits c-Myc via the Akt pathway and how JA inhibits Akt activation.

In conclusion, this study presented a mechanistic basis for the antitumor effects of JA and JB in PC3 cells through the induction of ROS, leading to a mitochondrial damage and DNA damage response and cell cycle arrest at the $\mathrm{G}_{1} / \mathrm{G}_{0}$ phase, owing to the decline of c-Myc, or $\mathrm{G}_{2} / \mathrm{M}$ phase arrest involving the activation of the JNK pathway. Animal trials will be needed to determine whether JA and JB are chemotherapeutic candidates.

\section{Acknowledgements}

This work was supported by the National Natural Science
Foundation of China (№ 81273533, 81473238, and 81473107).

\section{Author contribution}

Hui-qing YUAN and Yan-xia GUO designed the research; Yan-xia GUO, Mei-juan WANG and Yi-wen DONG performed the experiments; Hong-xiang LOU and Zhao-min LIN contributed the new reagents and analytic tools; Yan-xia GUO and Huan-min NIU analyzed the data; and Hui-qing YUAN, Charles YF YOUNG, and Yan-xia GUO wrote the paper.

\section{References}

1 Galsky MD, Small AC, Tsao CK, Oh WK. Clinical development of novel therapeutics for castration-resistant prostate cancer: historic challenges and recent successes. Ca-Cancer J Clin 2012; 62: 299308.

2 Attard G, Parker C, Eeles RA, Schröder F, Tomlins SA, Tannock I, et al. Prostate cancer. Lancet 2016; 387: 70-82.

3 Feldman BJ, Feldman D. The development of androgen-independent prostate cancer. Nat Rev Cancer 2001; 1: 34-45.

4 Jayaram A, Attard G. Prostate cancer: cabazitaxel-a key therapeutic option in prostate cancer. Nat Rev Urol 2015; 12: 312-3.

5 Ohlmann $\mathrm{CH}$. Chemotherapy of prostate cancer. Urologe 2015; 54: 1461-71.

6 Singh RP, Dhanalakshmi S, Agarwal R. Phytochemicals as cell cycle modulators a less toxic approach in halting human cancers. Cell Cycle 2002; 1: 156-61.

7 Wilken R, Veena MS, Wang MB, Srivatsan ES. Curcumin: a review of anti-cancer properties and therapeutic activity in head and neck squamous cell carcinoma. Mol Cancer 2011; 10: 12.

8 Watson JL, Greenshields A, Hill R, Hilchie A, Lee PW, Giacomantonio $\mathrm{CA}$, et al. Curcumin-induced apoptosis in ovarian carcinoma cells is p53-independent and involves p38 mitogen-activated protein kinase activation and down-regulation of $\mathrm{Bcl}-2$ and survivin expression and Akt signaling. Mol Carcinogen 2010; 49: 13-24.

9 Pandey MK, Sung B, Kunnumakkara AB, Sethi G, Chaturvedi MM, Aggarwal BB. Berberine modifies cysteine 179 of IkB $\alpha$ kinase, suppresses nuclear factor-kB-regulated anti-apoptotic gene products, and potentiates apoptosis. Cancer Res 2008; 68: 5370-9.

10 Mahata S, Bharti AC, Shukla S, Tyagi A, Syed A Husain SA, et al. Berberine modulates AP-1 activity to suppress HPV transcription and downstream signaling to induce growth arrest and apoptosis in cervical cancer cells. Mol Cancer 2011; 10: 39.

11 Liu YQ, Ji Y, Li XZ, Tian KL, Young CY, Lou HX, et al. Retigeric acid B-induced mitophagy by oxidative stress attenuates cell death against prostate cancer cells in vitro. Acta Pharmacol Sin 2013; 34: 118391.

12 Sauer H, Wartenberg M, Hescheler J. Reactive oxygen species as intracellular messengers during cell growth and differentiation. Cell Physiol Biochem 2001; 11: 173-86.

13 N'Guessan PD, Schmeck B, Ayim A, Hocke AC, Brell B, Hammerschmidt $\mathrm{S}$, et al. Streptococcus pneumoniae R6x induced p38 MAPK and JNKmediated caspase-dependent apoptosis in human endothelial cells. Thromb Haemost 2005; 94: 295-303.

14 Murakami T, Takagi H, Suzuma K, Suzuma I, Ohashi H, Watanabe D, et al. Angiopoietin-1 attenuates H2O2-induced SEK1/JNK phosphorylation through the phosphatidylinositol 3-kinase/Akt pathway in vascular endothelial cells. J Biol Chem 2005; 280: 31841-9.

15 Yang Y, Karakhanova S, Werner J, Bazhin AV. Reactive oxygen species in cancer biology and anticancer therapy. Curr Med Chem 2013; 20 : 3677-92. 
16 Kuystermans D, Al-Rubeai M. C-Myc increases cell number through uncoupling of cell division from cell size in $\mathrm{CHO}$ cells. BMC Biotechnol 2009; 9: 76.

17 Yao YL, Li C, Zhou XY, Zhang Y, Lu YL, Chen JH, et al. PIWIL2 induces c-Myc expression by interacting with NME2 and regulates C-Mycmediated tumor cell proliferation. Oncotarget 2014; 5: 8466-77.

18 Dang CV. MYC on the path to cancer. Cell 2012; 149: 22-35.

19 Jiang QP, Zhang YJ, Zhao MY, Li QL, Chen RC, Long XB, et al. miR-16 induction after CDK4 knockdown is mediated by c-Myc suppression and inhibits cell growth as well as sensitizes nasopharyngeal carcinoma cells to chemotherapy. Tumour Biol 2016; 37: 2425-33.

20 Zhang M, Fan HY, Li SC. Inhibition of C-Myc by 10058-F4 induces growth arrest and chemosensitivity in pancreatic ductal adenocarcinoma. Biomed Pharmacother 2015; 73: 123-8.

21 Lin ZM, Guo YX, Gao YH, Wang SQ, Wang XN, Xie ZY, et al. entKaurane diterpenoids from Chinese liverworts and their antitumor activities through michael addition as detected in situ by a fluorescence probe. J Med Chem 2015; 58: 3944-56.

22 Carroll AG, Voeller HJ, Sugars L, Gelmann EP. p53 oncogene mutations in three human prostate cancer cell lines. Prostate 1993; 23: 123-34.

23 Liu CX, Yin QQ, Zhou HC, Wu YL, Pu JX, Xia L, et al. Adenanthin targets peroxiredoxin I and II to induce differentiation of leukemic cells. Nat Chem Biol 2012; 8: 486-93.

24 Zhen T, Wu CF, Liu P, Wu HY, Zhou GB, Lu Y, et al. Targeting of AML1ETO in $t(8 ; 21)$ leukemia by oridonin generates a tumor suppressor-like protein. Sci Transl Med 2012; 4: 127ra38.

25 Kastan MB, Bartek J. Cell-cycle checkpoints and cancer. Nature 2004; 432: 316-23.

26 Golsteyn RM. Cdk1 and Cdk2 complexes (cyclin dependent kinases) in apoptosis: a role beyond the cell cycle. Cancer Lett 2005; 217: 129-38.

27 Davies MA, Koul D, Dhesi H, Berman R, McDonnell TJ, McConkey D, et al. Regulation of Akt/PKB activity, cellular growth, and apoptosis in prostate carcinoma cells by MMAC/PTEN. Cancer Res 1999; 59: 2551-6.

28 Graff JR, Konicek BW, McNulty AM, Wang ZJ, Houck K, Allen S, et al. Increased Akt activity contributes to prostate cancer progression by dramatically accelerating prostate tumor growth and diminishing p2 $7^{\text {Kip1 }}$ expression. J Biol Chem 2000; 32: 24500-5.

29 Reinhardt HC, Aslanian AS, Lees JA, Yaffe MB. p53-deficient cells rely on ATM- and ATR-mediated checkpoint signaling through the p38MAPK/MK2 pathway for survival after DNA damage. Cancer Cell 2007; 11: 175-89.
30 Amanullah A, Liebermann DA, Hoffman B. p53-independent apoptosis associated with c-Myc-mediated block in myeloid cell differentiation. Oncogene 2000; 19: 2967-77.

31 Zeng W, Sun HY, Meng FK, Liu ZM, Xiong J, Zhou S, et al. Nuclear C-MYC expression level is associated with disease progression and potentially predictive of two year overall survival in prostate cancer. Int J Clin Exp Pathol 2015; 8: 1878-88.

32 Nawal B, Bénédicte L, Jean Marie B. Cell cycle, cytoskeleton dynamics and beyond: the any functions of cyclins and CDK inhibitors. Cell Cycle 2015; 14: 1786-98.

33 Liao YJ, Bai HY, Li ZH, Zou J, Chen JW, Zheng F, et al. Longikaurin A, a natural ent-kaurane, induces $\mathrm{G}_{2} / \mathrm{M}$ phase arrest via down-regulation of Skp2 and apoptosis induction through ROS/JNK/c-Jun pathway in hepatocellular carcinoma cells. Cell Death Dis 2014; 5: e1137.

34 Trzeciak AR, Nyaga SG, Jaruga P, Lohani A, Dizdaroglu M, Evans MK. Cellular repair of oxidatively induced DNAbase lesions is defective in prostate cancer cell lines, PC-3 and DU-145. Carcinogenesis 2004; 25: $1359-70$.

35 Yang J, Yu Y, Hamrick HE, Duerksen-Hughes PJ. ATM, ATR and DNA-PK: initiators of the cellular genotoxic stress responses. Carcinogenesis 2003; 24: 1571-80.

36 Lees-Miller SP, Meek K. Repair of DNA double strand breaks by nonhomologous end joining. Biochimie 2003; 85: 1161-73.

37 Lisby M, Rothstein R. DNA damage checkpoint and repair centers. Curr Opin Cell Biol 2004; 16: 328-34.

38 Wang Q, Lasset C, Desseigne F, Saurin JC, Maugard C, Navarro C, et al. Prevalence of germline mutations of hMLH1, hMSH2, hPMS1, hPMS2, and hMSH6 genes in 75 French kindreds with nonpolyposis colorectal cancer. Hum Genet 1999; 105: 79-85.

39 Chalermrujinanant C, Michowski W, Sittithumcharee G, Esashi F, Jirawatnotai S. Cyclin D1 promotes BRCA2-Rad51 interaction by restricting cyclin A/B-dependent BRCA2 phosphorylation. Oncogene 2015. doi: 10.1038/onc.2015.354.

40 Kyriakis JM, Banerjee P, Nikolakaki E, Dai T, Rubie EA, Ahmad MF, et al. The stress-activated protein kinase subfamily of c-Jun kinases. Nature 1994; 369: 156-60.

41 Chien CC, Wu MS, Shen SC, Ko CH, Chen CH, Yang LL, et al. Activation of JNK contributes to evodiamine-induced apoptosis and $\mathrm{G}_{2} / \mathrm{M}$ arrest in human colorectal carcinoma cells: a structure-activity study of evodiamine. Plos One 2014; 9: e99729.

42 Quan YZ, Wang NT, Chen QQ, Xu J, Chen W, Di MJ, et al. SIRT3 inhibits prostate cancer by destabilizing oncoprotein c-MYC through regulation of the PI3K/Akt pathway. Oncotarget 2015; 6: 26494-507. 